\title{
LA ENSEÑANZA DE LA COMUNICACIÓN EN LA ESCUELA SECUNDARIA EN MENDOZA: PROPUESTAS PARA UN ABORDAJE CRÍTICO DEL DISEÑO CURRICULAR
}

NORA LLAVER

Universidad Nacional de Cuyo, Argentina / norallaver@gmail.com

BetTINA MARTINO²

Universidad Nacional de Cuyo, Argentina / bamartino@hotmail.com

Recibido: 17/4/2019/ Aceptado: 18/7/2019

doi: $10.26439 /$ contratexto2019.n032.4616

Resumen. El presente artículo muestra los resultados de un trabajo de investigación desarrollado en dos etapas entre el 2013 y el 2017. En la primera etapa, el objetivo principal fue reconstruir las representaciones de profesores de comunicación social de escuelas secundarias en Mendoza (Argentina) en torno de la enseñanza de la comunicación; en la segunda, y en continuidad con la anterior, se analizaron y resignificaron los contenidos del Diseño Curricular Provincial de la misma materia, teniendo en cuenta la perspectiva de la educación mediática crítica (EMC). Se parte del presupuesto de que no hay educación para los medios que pueda llamarse "crítica" si los puntos de partida al concebir los procesos de enseñanza y aprendizaje y la consideración del universo mediático y tecnológico no lo son. A partir de las comprensiones ofrecidas por las teorías de la resistencia en la educación, las teorías críticas del currículo y la EMC, se analiza e interpela el conjunto de contenidos sobre la comunicación ofrecido a los jóvenes en el ámbito escolar. Interesa en este artículo retomar algunos interrogantes que fueron parte de la investigación: ¿En qué consiste la dimensión crítica de la educación mediática? ¿Qué posicionamientos pedagógicos la hacen posible? ¿Qué abordajes debería priorizar una educación mediática que se diga a sí misma crítica? ¿Cómo interrogar los diseños

1 Doctora en Ciencias de la Educación por la Universidad Nacional de Cuyo, Argentina. https://orcid. org/0000-0002-1998-552X

2 Doctoranda en Ciencias Sociales por la Universidad Nacional de Cuyo, Argentina. https://orcid.org/00000003-0072-4992 
curriculares y las planificaciones desde una perspectiva crítica para evitar la reproducción de las formas de comunicación hegemónicas?

Palabras clave: comunicación / educación / currículo / pensamiento crítico / educación mediática

\title{
TEACHING OF COMMUNICATION AT SECONDARY SCHOOLS IN MENDOZA: PROPOSALS FOR A CRITICAL APPROACH TO CURRICULUM DESIGN
}

\begin{abstract}
This article shows the results of a research conducted in two stages between 2013 and 2017. In the first stage, the main objective was to reconstruct the representations of Social Communication teachers from secondary schools in Mendoza (Argentina) around teaching of communication. In the second stage, as a continuation of the previous one, the contents of the Provincial Curricular Design of the same subject were analyzed and resignified, taking into account the perspective of the critical media education (EMC). The assumption is that no media education can be called "critical" if the starting points when designing the processes of teaching and learning, and understanding the universe of media and technologies are not so. On the basis of the insights offered by the theories of resistance in education, critical curriculum theories and EMC, the contents on communication offered to school students are analyzed and challenged. This article is aimed at taking up again some questions that were part of the research: What is the critical dimension of media education? What pedagogical positions make it possible? What approaches should be prioritized in a really critical media education? How to question the curricular designs and schedules from a critical perspective to avoid the reproduction of hegemonic forms of communication?
\end{abstract}

Keywords: Communication / education / curriculum / critical thinking / media education 


\section{O ENSINO DA COMUNICAÇÃO NA ESCOLA SECUNDÁRIA EM MENDOZA: PROPOSTAS PARA UMA ABORDAGEM CRÍTICA DO DESENHO CURRICULAR}

Resumo. Este artigo apresenta os resultados de um trabalho de pesquisa desenvolvido em duas etapas entre 2013 e 2017. Na primeira etapa, o objetivo principal foi reconstruir as representações de professores de Comunicação Social de escolas secundárias em Mendoza (Argentina) em torno ao ensino da comunicação; no segundo momento, e em continuidade com o anterior, foram analisados e resignificados os conteúdos do Projeto Curricular Provincial do mesmo curso, considerando a perspectiva da Educação Crítica em Mídia (EMC). Baseia-se no pressuposto de que não há educação para a mídia que possa ser chamada de "crítica" se os pontos de partida ao conceber os processos de ensino e aprendizagem e a compreensão da mídia e do universo tecnológico não forem também críticos. Com base nos conhecimentos oferecidos pelas teorias da resistência na educação, nas teorias críticas do currículo e na EMC, analisamos e questionamos o conteúdo sobre a comunicação que é oferecido aos jovens na escola. Interessa neste artigo retomar algumas questões que fizeram parte da pesquisa: o que é a dimensão crítica da educação midiática? Que posicionamentos pedagógicos tornam ela possível? Quais abordagens deve priorizar a educação crítica para se tornar crítica? Como devem-se questionar os desenhos curriculares e agendas a partir de uma perspectiva crítica para evitar a reprodução de formas de comunicação hegemônica?

Palavras chave: comunicação / educação / currículo / pensamento crítico / educação midiática 


\section{INTRODUCCIÓN}

La educación mediática puede ser concebida como un conjunto de abordajes y acciones tendentes a promover la reflexión sobre las culturas mediática y, actualmente, de la conectividad, así como de nuestra inmersión en ellas. En su vertiente crítica, parte del reconocimiento de que los medios y las tecnologías impactan fuertemente en las formas de socialización y en la construcción de la subjetividad, particularmente por la creciente tecnificación y mercantilización que experimentan.

Las representaciones sociales, los sentidos de la experiencia, la consideración de los "otros/as mediatizados" que generan medios y tecnologías, así como el atravesamiento cada vez mayor que hacen de las diversas esferas de la vida social ${ }^{3}$, coadyuvan a construir imágenes y comprensiones del mundo a partir de un discurso monocorde que naturaliza y oculta la desigualdad, homogeneiza la variedad de experiencias culturales, invisibiliza las subalternidades, refuerza los estereotipos de género, raza y origen social, además de promover líneas demarcatorias de inclusión/exclusión conforme los criterios de aparición y visibilidad propios de los medios tradicionales, o bien de visibilidad y aprobación promovidos por las plataformas digitales (likes, cantidad de veces que ha sido visto o reproducido un posteo, asiduidad de aparición, entre otros).

Si bien un programa de educación mediática puede desarrollarse a lo largo de toda la vida en cualquier espacio educativo u organización social, existe la necesidad de crear instancias dirigidas particularmente a niñas, niños y jóvenes, poblaciones que se consideran altamente vulnerables en las culturas mediáticas y de la conectividad. El espacio escolar, a su vez, aparece como un lugar propicio para llevar adelante acciones de educación para los medios y, conforme esto, surge la necesidad de capacitar a profesores que se desempeñen en las intersecciones de la comunicación/educación.

En los últimos veinte años Argentina experimentó una creciente inclusión de contenidos, espacios y proyectos de educación para los medios en el ámbito escolar; asimismo, las carreras de comunicación social incorporaron materias, orientaciones e instancias de posgrado relacionadas con la comunicación/educación y las universidades han dado lugar a la creación de profesorados en la materia4.

3 Nos referimos, por ejemplo, no solo a las representaciones mediáticas circulantes que afectan nuestra comprensión del mundo que nos rodea, sino también a otros atravesamientos de la cotidianeidad, como el uso de aplicaciones de citas en las relaciones sexoafectivas, o para cuantificar nuestro gasto calórico, cantidad de ejercicio diario, ingesta de agua, etc., alarmas y recordatorios permanentes, entre tantos otros aspectos.

4 En Argentina, los contenidos transversales y específicos relacionados con la educación para los medios fueron incorporados explícitamente en 1993 con la Ley Federal de Educación 24.195. A partir del 2006, la Ley 26.206 de Educación Nacional refuerza la necesidad de la educación mediática y agrega la de reducir la brecha digital. El Ministerio de Educación, Ciencia y Tecnología llevó adelante políticas públicas tendentes a concretar el cumplimiento de los objetivos de la nueva 
Aunque lo anterior constituye un avance alentador, aún es una tarea inconclusa la reflexión acerca de los aspectos epistemológicos, teóricos y metodológicos que son propios de una educación para los medios que pueda denominarse crítica, y que entienda esa condición como mucho más que el objetivo de formar niñas, niños y jóvenes críticos frente a los medios de comunicación y las tecnologías. Desde una perspectiva más amplia, para que la educación mediática sea crítica, tanto los posicionamientos pedagógicos para la enseñanza cuanto los saberes involucrados en ella han de responder a paradigmas críticos, que no solo deben ser explicitados, sino también sostenidos durante todo el proceso educativo.

En lo que sigue, se presenta un trabajo de investigación desarrollado entre el 2013 y el $2017^{5}$, financiado y ejecutado por la Secretaría de Ciencia, Técnica y Posgrado de la Universidad Nacional de Cuyo (Mendoza, Argentina). Dicho trabajo se ocupó, en un primer momento, de reconstruir las representaciones que los docentes de comunicación social de las escuelas secundarias de Mendoza tenían acerca de la enseñanza de la comunicación y de la formación de sujetos críticos frente a los medios; en una segunda instancia, y en continuidad con lo anterior, se propuso analizar y resignificar los contenidos del diseño curricular de la materia Comunicación Social dictada en los colegios secundarios ${ }^{6}$, teniendo en cuenta la perspectiva de la educación mediática crítica (EMC), que autores como Len Masterman (1993a, 1993b), David Buckingham (2005) o, especialmente, Douglas Kellner $(1998,2011)$, conjuntamente con Jeff Share (Kellner y Share, 2005) han llevado adelante.

La materia Comunicación Social fue creada en Mendoza en el año 1998. En Argentina, ya desde los primeros años de la década del 80, la actuación de los medios de comunicación durante la guerra de Malvinas y el retorno a la democracia fue fundamental para la introducción de acciones de educación mediática pensadas como una herramienta de fortalecimiento ciudadano (Morduchowicz, 2017). También la Ley Federal de Educación (1993), primero, y la Ley de Educación Nacional (2006), después, propiciaron la incorporación de la temática en los distintos niveles, lo cual implicó el surgimiento de iniciativas

ley en la materia. En relación con las carreras de comunicación social, muchas incluyeron y aún sostienen asignaturas y orientaciones relacionadas con las articulaciones entre comunicación y educación, y con el uso de las NTIC como herramientas pedagógicas; respecto de los profesorados en comunicación, fueron creados a partir de los años 90 en las universidades tanto de gestión pública como privada, en virtud de la creciente incorporación de la temática en el ámbito escolar.

5 El trabajo de investigación comprendió dos proyectos: "Representaciones docentes sobre la formación del pensamiento crítico y prácticas áulicas en la educación mediática en el nivel secundario en Mendoza" (Llaver y Martino, 2015) y "La enseñanza de la comunicación en la escuela secundaria. Resignificación del currículum desde la educación mediática crítica” (Llaver y Martino, 2017).

6 En Argentina, los niveles educativos obligatorios son inicial (salas de 4 y 5 años), primario (6 a 12/13 años) y secundario (13 a 17/18 años). El nivel secundario va de primero a quinto año y la materia a la que hacemos referencia, Comunicación Social, es dictada en primero o segundo año, según la decisión de cada escuela. 
diversas en el país. Mendoza fue la única provincia que logró en forma temprana la incorporación de una materia específica, con un espacio y un diseño curricular propios y con dictado obligatorio, destinada a jóvenes de 13 a 15 años. La propuesta propició un acercamiento real a la educación para los medios, que hasta hoy mantiene su vigencia y es fuente de trabajo de gran cantidad de graduados de la Licenciatura en Comunicación Social.

En el año 2014 se inició un proceso de reforma curricular en todo el país que afectó la escuela secundaria. La materia continuó vigente y se insistió en sostener su objetivo de promover herramientas para el análisis crítico de los medios, incorporando, además, algunos contenidos que los profesores habían incluido de hecho (por ejemplo los relacionados con las nuevas tecnologías o las redes sociales). Sin embargo, implicó también la pérdida de horas para profesores y de algunas incumbencias disciplinares que podrían haberse incorporado al área de comunicación. La reforma se llevó adelante con tensiones, aunque no solamente en esa área.

\section{ASPECTOS RELEVANTES DE LA INVESTIGACIÓN}

La primera investigación realizada entre el 2013 y el 2015, denominada "Representaciones docentes sobre la formación del pensamiento crítico en la educación mediática en el nivel secundario en Mendoza", permitió contar con una caracterización del sentido que los profesores daban a la enseñanza de la comunicación, los saberes priorizados y las formas en que estos eran desarrollados. Se trabajó en ese periodo a partir de 8 entrevistas exploratorias que permitieron un primer acercamiento al campo y ayudaron a identificar tópicos para profundizar, los cuales fueron incluidos luego en la realización de 16 entrevistas semiestructuradas. Complementariamente, para obtener un control cruzado de datos (Taylor y Bogdan, 1994), se analizó un corpus de materiales de trabajo (cuadernillos, evaluaciones, trabajos prácticos, carpetas de estudiantes) y planificaciones, además de la observación de dos clases.

Respecto de la importancia de enseñar comunicación social, los profesores coincidían en la necesidad de ayudar a develar los mecanismos de producción de mensajes de los medios de comunicación. Es decir, visibilizar aquello que estos presentan como natural, cuando en realidad es construido. La estrategia de mostrar dicho carácter construido de los mensajes y discursos mediáticos se reflejaba en las respuestas de los entrevistados a través de un uso recurrente de metáforas "visuales" ("abrir los ojos", "tener mirada atenta", "tener diversos puntos de vista", "poder ver lo que hay detrás"). Asimismo, se encontró que los temas centrales de trabajo eran los modelos de comunicación, la noticia, la imagen (especialmente fotografía) y la propaganda y la publicidad, y, dentro de ellos, el análisis de estereotipos. Mayoritariamente, la estrategia didáctica elegida era la del análisis de casos y, luego de eso, la producción de mensajes propios, siempre en relación con el género/formato/soporte que se estuviera enseñando. 
Sin embargo, el eje de oposición natural/construido es apenas uno de los aspectos que hacen una EMC. De ahí la decisión de emprender la segunda y última etapa de investigación (2016-2017) con el proyecto "La enseñanza de la comunicación en la escuela secundaria. Resignificación del currículum desde la educación mediática crítica", centrado en el análisis e interrogación crítica de los contenidos que forman parte del Diseño Curricular Provincial (DCP) de Comunicación Social, cuyos resultados se muestran sucintamente en el presente artículo.

La EMC se define no como un corpus de conceptos y metodologías de trabajo, sino como un conjunto de estructuras conceptuales de comprensión (Kellner y Share, 2005) del funcionamiento de medios y tecnologías, y de sus alcances en términos de las formaciones socioculturales en las que se inscriben y a las cuales coproducen. Estas estructuras conceptuales, ancladas en el pensamiento social crítico, incluyen aspectos cruciales como el poder, la hegemonía, las desigualdades, la subalternidad, las operaciones de naturalización. Es a partir de esa comprensión que se considera posible delinear y desarrollar programas y proyectos de educación para los medios con una perspectiva crítica.

Establecer ese diálogo entre diseño curricular y EMC suponía, también, reflexionar acerca de los puntos de partida pedagógicos que son condición de posibilidad de un proceso de enseñanza y aprendizaje críticos. Es por eso que gran parte del encuadre teórico de la investigación se situó en el campo de las teorías de la resistencia en la educación (Apple, 1989; Giroux, 1990, 1992, 2004; McLaren, 1984; Freire, 1977, 1993) y las perspectivas críticas del currículum (Da Silva, 1997, 1999).

Tomando los resultados de la investigación anterior y a partir del abordaje de las características particulares de la EMC y de los posicionamientos pedagógicos necesarios para su desarrollo, se avanzó sobre el análisis y resignificación de los temas del Diseño Curricular Provincial, y se propuso una interrogación y una recreación de los contenidos a partir de los postulados de la EMC. El producto de este trabajo se volcó en un libro con artículos teóricos y propuestas prácticas para la enseñanza de la comunicación en la escuela y un reservorio online de recursos para trabajar temas de comunicación en el aula desde una perspectiva crítica, ambos actualmente en etapa de diseño y edición. Lo expuesto en este artículo es una síntesis de aquellos aspectos más significativos del trabajo de investigación ya citado.

\section{LA MATERIA COMUNICACIÓN SOCIAL COMO PROGRAMA DE EDUCACIÓN PARA LOS MEDIOS}

El antecedente más inmediato de la creación de la materia Comunicación Social en las escuelas secundarias de Mendoza fue un conjunto de talleres implementados en forma dispar y variada: plástica, música, comunicación social y teatro, que se repartían los 
meses del año lectivo para su dictado. Se tomó la experiencia pedagógica desarrollada en los talleres de comunicación y se profundizaron sus contenidos. Si bien en un principio aparecía entremezclada y con límites difusos con lo artístico o los saberes de lengua, luego de la reforma del 2014 pasó a formar parte de un área específica denominada comunicación.

Desde sus comienzos, la materia planteó la responsabilidad del sistema escolar de abordar aspectos fundamentales de la cultura mediática, haciendo hincapié en la necesidad de desarrollar un pensamiento divergente y crítico en relación con los consumos culturales de los jóvenes, tanto por la vía del análisis como de la producción de mensajes y productos comunicacionales propios.

La idea de formar espectadores críticos frente a los medios aparece con claridad en la propuesta original de creación de la materia en 19997. En el documento que contiene la propuesta se distingue, además, lectura crítica de lectura ideológica, definiéndose la primera como un tipo de lectura que presupone una toma de distancia del objeto y la posesión de criterios de análisis y evaluación objetivos (universales y fundados) y pertinentes (adecuados para un determinado tipo de objeto).

Como ya se ha expresado, en el año 2014 se inicia un proceso de reforma curricular en todo el país que afectó la escuela secundaria. El equipo de trabajo a cargo de la nueva propuesta, continuando con la forma de trabajo ya establecida, reformuló los contenidos a enseñar sobre la comunicación teniendo en cuenta dos ejes: la competencia comunicativa y la alfabetización mediática. La primera se refiere a "las habilidades que todos desarrollamos para relacionarnos y entendernos con los otros, produciendo diferentes mensajes, para leer objetos de sentido producidos por la cultura y la sociedad"; la segunda, alude a "tener acceso y comprender la multiplicidad de mensajes mediáticos, en los que se reflejan las representaciones del mundo que nos rodea", que afectan a su vez todos los planos de la vida cotidiana y de relación (Diseño Curricular Provincial [DCP], 2015, p. 203).

La reforma introdujo algunas nuevas consideraciones: por un lado, la necesidad de pensar acerca de cómo los jóvenes son insistentemente interpelados por los medios de comunicación en tanto consumidores y la importancia, frente a esto, de fortalecer una ciudadanía comunicacional; por otro, situar la escuela como espacio privilegiado y propicio para dar el debate acerca de medios y tecnologías y propiciar la reflexión sobre el acceso a los bienes culturales (materiales y simbólicos).

7 Dicha propuesta fue plasmada en el documento Renovación curricular en la provincia de Mendoza. Educación Artística y Comunicación Social. Propuesta curricular de Educación Artística y Comunicación Social para el tercer ciclo de la educación general básica. (Dirección General de Escuelas-Gobierno de Mendoza, 1999). 
Tabla 1

Contenidos del diseño curricular de Comunicación Social 2015, Mendoza, Argentina

\begin{tabular}{|c|c|c|}
\hline Eje & $\begin{array}{l}\text { Saberes de Comunicación } \\
\text { Social } \\
1 .^{\circ} \text { ○ } 2 .^{\circ} \text { año del ciclo básico }\end{array}$ & Aprendizajes específicos \\
\hline \multirow{4}{*}{$\begin{array}{l}\text { LA COMUNICACIÓN } \\
\text { COMO PRÁCTICA } \\
\text { SOCIAL }\end{array}$} & $\begin{array}{l}\text { Reconocer, diferenciar y resig- } \\
\text { nificar modelos del proceso } \\
\text { comunicativo: clásico y semió- } \\
\text { tico, y los elementos que lo } \\
\text { componen. }\end{array}$ & $\begin{array}{l}\text { - Reconocimiento de diversos procesos de } \\
\text { comunicación, autoritarios, dialógicos, demo- } \\
\text { cráticos y otros. } \\
\text { - Relación entre el nuevo conocimiento } \\
\text {-modelo semiótico- con sus ideas previas } \\
\text {-modelo clásico-. } \\
\text { - Descripción y análisis del proceso comu- } \\
\text { nicacional desde un enfoque semiótico. }\end{array}$ \\
\hline & $\begin{array}{l}\text { Analizar diferentes } \\
\text { situaciones comunicativas y } \\
\text { reconocer los diversos tipos } \\
\text { de comunicación, teniendo } \\
\text { en cuenta su contexto de } \\
\text { producción. }\end{array}$ & $\begin{array}{l}\text { - Identificación de los elementos del modelo } \\
\text { comunicativo. } \\
\text { - Reconocimiento de las categorías utilizadas } \\
\text { para clasificar tipos de comunicación. } \\
\text { - Descripción del contexto en las situaciones } \\
\text { comunicativas analizadas. }\end{array}$ \\
\hline & & $\begin{array}{l}\text { - Identificación de los vínculos que se establecen } \\
\text { en la construcción de mensajes, relaciones } \\
\text { autoritarias, de igualdad, de colaboración, etc. }\end{array}$ \\
\hline & $\begin{array}{l}\text { Producir, modificar y criticar } \\
\text { mensajes de manera } \\
\text { consciente y pertinente } \\
\text { utilizando recursos y técnicas } \\
\text { variadas }\end{array}$ & $\begin{array}{l}\text { - Manejo de los diversos tipos de comunicación } \\
\text { y sus lenguajes para poder comprender y } \\
\text { producir mensajes. } \\
\text { - Ampliación y estructuración del vocabulario } \\
\text { a partir de las situaciones de comprensión y } \\
\text { producción de mensajes. } \\
\text { - Utilización de diferentes soportes de comuni- } \\
\text { cación para la construcción de mensajes en } \\
\text { su contexto, teniendo en cuenta el acceso } \\
\text { generalizado a las nuevas tecnologías de } \\
\text { comunicación. } \\
\text { - Producción de mensajes utilizando las redes } \\
\text { sociales en los entornos virtuales y aplicando } \\
\text { criterios éticos. }\end{array}$ \\
\hline \multirow{2}{*}{$\begin{array}{l}\text { LA COMUNICACIÓN } \\
\text { Y LOS MEDIOS } \\
\text { MASIVOS }\end{array}$} & $\begin{array}{l}\text { Comprender la historia de los } \\
\text { medios masivos, desde sus } \\
\text { inicios hasta la aparición de } \\
\text { los medios electrónicos y los } \\
\text { digitales. }\end{array}$ & $\begin{array}{l}\text { - Contrastación e interpretación de diferentes } \\
\text { discursos mediáticos. } \\
\text { - Reconstrucción de la historia de los medios } \\
\text { masivos en el contexto global, regional y local. }\end{array}$ \\
\hline & $\begin{array}{l}\text { Reconocer las particularidades } \\
\text { de la construcción de la } \\
\text { publicidad en los medios } \\
\text { masivos. }\end{array}$ & $\begin{array}{l}\text { - Identificación de componentes utilizados para } \\
\text { la comprensión y la producción de diferentes } \\
\text { mensajes publicitarios. } \\
\text { - Elaboración de diferentes mensajes } \\
\text { mediáticos en diversos formatos y lenguajes. }\end{array}$ \\
\hline
\end{tabular}


Analizar en las imágenes las - Observación e identificación de los elementos representaciones sociales que técnicos y expresivos de las imágenes.

proponen losmedios masivos - Observación y análisis de mensajes provenientes de comunicación a partir del de diferentes medios masivos e interpretación de uso de los estereotipos. diferentes textos para reconocer la función que cumplen los códigos de representación.

- Reconocimiento de las características de los estereotipos, valores y modelos para llegar a la desnaturalización.

Conocer y diferenciar los - Contrastación de distintos textos mediáticos géneros discursivos mediá- considerando la multiplicidad de formatos en que ticos y sus resignificaciones a se presenta la información.

partir delas TIC e interpretar - Reconocimiento de estructuras comunicativas formatos textuales con estruc- hipertextuales no lineales, para ampliar el turas comunicativas hiper- concepto de texto dirigido a la combinación de textuales no lineales. discursos verbales con recursos audiovisuales (imágenes, sonidos, videos, entre otros).

LA COMUNICACIÓN Y LOS MEDIOS MASIVOS
- Reconocimiento del impacto, alcance y riesgos que implican los mensajes en redes sociales y entornos colaborativos.

Analizar los procesos de uso - Reconocimiento de estructuras comunicativas y los impactos de las nuevas hipertextuales no lineales ampliando el concepto tecnologías como medios de texto dirigido a la combinación de discursos masivos de comunicación. verbales con recursos audiovisuales (imágenes, sonidos, videos entre otros).

- Producción de mensajes con distintos soportes y formatos mediáticos y tecnológicos.

Producir mensajes utilizando - Realización de producciones radiales escolares variedad de formatos mediá- contextualizadas.

ticos (radiales, periódicos, - Organización del periódico o diario mural de la afiches, audiovisuales, etc.). escuela.

- Realización de imágenes fijas para dar a conocer ideas propias surgidas a partir de diferentes propuestas problemáticas.

- Producción mediática con abordaje interdisciplinario teniendo en cuenta la intención, los destinatarios, las posibilidades tecnológicas y la información obtenida.

Fuente: Diseño Curricular Provincial Secundario - Dirección General de Escuelas - Subsecretaría de Planeamiento y Evaluación de la Calidad Educativa - Dirección de Planificación de la Calidad Educativa. (Diseño Curricular Provincial, 2015)

Si bien se realizaron jornadas de consulta y validación sobre una versión preliminar del nuevo diseño curricular en las escuelas, los profesores han expresado algunas discrepancias en relación con los contenidos teóricos (algunos aún deudores casi de 
manera exclusiva de la perspectiva semiótica), la mezcla de perspectivas conceptuales y la necesidad de poner en discusión los recortes realizados. Aun así, reconocen su formulación amplia como una ventaja, en la medida en que les permite tomarlo como un marco dentro del cual pueden realizarse adaptaciones y adecuaciones. Ciertamente, se pone de relieve aquí el hecho de que el currículum, al decir de Tadeu da Silva (1999), es un territorio político.

\section{UNA MIRADA CRÍTICA SOBRE EL CURRÍCULO Y SUS POSIBILIDADES}

Al analizar los contenidos para la enseñanza de la comunicación, se ingresa al terreno del currículo. Aproximarse al currículo escolar requiere partir de ciertos interrogantes que interesan de modo directo a los estudiantes que transitan las aulas y a los docentes a cargo de la enseñanza. ¿Qué se debe enseñar? ¿Cuáles son los objetivos de la enseñanza y qué actitudes y conocimientos están implicados en ellos? ¿Quiénes seleccionan los contenidos que la escuela distribuye socialmente? ¿Cuáles son las representaciones que tienden a perpetuarse? ¿Es posible modificarlas? ¿Qué dinámicas y procesos se ponen en juego desde el ámbito de la gestión política hasta las prácticas escolares en las aulas? ¿Cuál es el lugar de los docentes a la hora de definir qué, cómo y cuándo enseñar y evaluar? ¿Es posible que todo el estudiantado acceda igualmente a las formas consideradas "legítimas" de conocimiento? ¿Cuán relevante puede llegar a ser el currículo para abordar la vida social en una época de turbulencias? ¿Qué pasa con la ideología? Sin duda no existe una única y sencilla respuesta a estos interrogantes.

El currículo escolar -y la transmisión del conocimiento socialmente significativoimplica pensar críticamente y colectivamente los procesos y las problemáticas que surgen en su abordaje desde la configuración y el desarrollo en el ámbito político de la educación, hasta su despliegue en las aulas y, sobre todo, desde el lugar como docentes a la hora de la intervención.

El currículo actúa como regulador de la práctica docente y su impronta se manifiesta en las propuestas de enseñanza. A la vez, los docentes definen los criterios de selección y el modo de organizar los contenidos, los materiales para la enseñanza, es decir, moldean el currículo. Ahora bien, es posible situarse en el campo ${ }^{8}$ del currículo como actores/ as de la educación que elaboran su discurso y establecen sus prácticas educativas, u obrar como reproductores/as en el complejo marco de un producto que es histórico y

8 Aludimos expresamente al concepto desarrollado por Pierre Bourdieu, quien se refiere a un espacio social específico (en este caso el campo educacional-cultural) en el que diversas/os actoras/es e instituciones compiten por la posesión y el control de los bienes (saberes, poder, estatus, propiedad) que aseguran posiciones de jerarquía en los intercambios que se producen dentro de él. Cada campo social se constituye y organiza en torno a conflictos y posiciones (dominante/dominada). 
social. En cada uno de los ámbitos de decisión curricular juegan actores/as que pugnan, disputan, resisten, entramados en relaciones de poder donde se instituyen márgenes e intersticios de acción posible. Solo desde una aproximación crítica - conscientes de las fuerzas que actúan condicionando prácticas y saberes-los docentes podrán insertarse en contextos institucionales/áulicos y propiciar acciones transformadoras. En otras palabras, las disputas que se producen en la producción y la selección político-cultural del contenido por enseñar son una muestra de las relaciones de poder que actúan y los intereses que se juegan (Llaver, 2019). Pero a la vez, las formas en que los profesores moldean el currículo visibiliza los intersticios en los que es posible usar el espacio definido por otros para producir transformaciones significativas actuando tácticamente, según entiende este concepto Michel de Certeau (2000)9.

En la práctica cotidiana, estas dimensiones problematizadoras del currículo aparecen invisibilizadas bajo la percepción naturalizada de que el currículo es el documento que contiene "lo que hay que dar". En ese sentido, es un texto que es vivido como algo exterior, que viene "de arriba", de las instancias decisoras. Desde este punto de vista, sería "la prescripción - unificada, sistemática, oficial, escrita- de lo que se debe transmitir y de lo que se debe hacer en la escuela" (Gvirtz y Palamidessi, 1998, p. 54). En ocasiones, en lugar de cuestionar los recortes que operan en el currículo y para evitar conflictos con la administración escolar - muy afecta a vigilar el cumplimiento con planificaciones, llenado de libros de temas, evaluaciones, entre otras herramientas- los profesores desarrollan un currículo paralelo puertas adentro del aula.

El currículo, como el conjunto de contenidos que han sido definidos y explícitamente indicados para ser enseñados, existe, según afirman Gvirtz y Palamidessi (1998) porque es necesario tener objetos identificados, secuenciados y ordenados frente a la compleja tarea de enseñanza. Estos contenidos son producidos generalmente por instituciones exteriores a la escuela, que actúan como referencia y autoridad cultural en la materia. En el caso de la enseñanza de la comunicación, esta referencia no ha sido siempre el campo académico, puesto que durante mucho tiempo los contenidos relacionados con la temática fueron generados y abordados desde el área de lengua y en las intersecciones con el discurso y las prácticas periodísticas. Pero la progresiva consolidación de un saber y prácticas académicas sobre la comunicación, sumada al peso que fue adquiriendo la problemática de lo mediático, en relación, no solo con el funcionamiento de lo social, sino

9 En su distinción entre estrategias y tácticas, Michel de Certeau considera estas últimas como "artes de hacer", cazares furtivos, oportunidades de acción siempre en relación con un sistema de reglas que las encuadra pero que se apartan de la reproducción. Las tácticas, según el autor, "ponen sus esperanzas en una hábil utilización del tiempo, en las ocasiones que presenta y también en las sacudidas que introduce en los cimientos de un poder". De Certeau, M. (2000). La invención de lo cotidiano I. Artes de hacer. México: Universidad Iberoamericana. Departamento de Historia. Instituto Tecnológico y de Estudios Superiores de Occidente, p. 45. 
también en relación con los jóvenes y con la escuela, produjo una "contenidización" de lo comunicacional. Es decir que el saber socialmente producido en el ámbito comunicacional fue organizado en cuerpos de conocimiento o, mejor dicho, de contenidos por enseñar.

Al hablar de la enseñanza de la comunicación, ese proceso de contenidización a que se alude y que se expresa en el conjunto de contenidos volcados en el diseño curricular, teje un entramado con otros saberes con los que se superpone (las artes, la lengua, la formación ética y ciudadana), con las tensiones que se generan con ellos (¿Quién dicta este contenido? ¿Por qué lo desarrolla el área de lengua? ¿Por qué el área de comunicación - de existencia autónoma- sigue siendo coordinada por profesoras/es de lengua y literatura?), con las disposiciones de la dirección escolar que se experimentan como facilitadoras/obstaculizadoras, con las posibilidades que da o quita la infraestructura con que se cuenta para "hacer comunicación" (la conectividad, el acceso a un celular con datos móviles, si es posible o no hacer audiovisual o hay que "conformarse" con trabajar con materiales impresos que ya no son parte del consumo de los jóvenes), con las demandas de la escuela de ser visibilizada a partir de las producciones comunicacionales (las participaciones en los concursos, la creación de un diario mural, de un programa de radio; comunicar, estar en contacto, aunque no se sepa bien para qué) y hasta con la relación entre los/as mismos/as profesores/as de comunicación (uso de un cuadernillo unificado para evitar problemas en las mesas de exámenes cuando se tienen perspectivas de trabajo divergentes) (Martino, 2019).

La tarea de interpelar y resignificar el currículo desde los postulados de la EMC debe tener en cuenta esta complejidad y ha de partir de la reflexión acerca de cuál es el recorte operado en los contenidos comunicacionales seleccionados, a la vez que cuestionar -a partir de esos contenidos- la manera en que podrían ser interrogados críticamente.

\section{POSICIONAMIENTOS NECESARIOS PARA UNA EDUCACIÓN QUE ENSEÑE A PENSAR}

En la medida en que no se especifique desde qué concepción de conocimiento se trabaja, cuáles son los saberes que se decide abordar, cómo se entiende a los sujetos del aprendizaje, cuáles son los grupos sociales con los que se emprende la acción educativa, en qué contexto histórico se sitúa la experiencia, no será posible avanzar en la construcción de una propuesta de enseñanza válida y significativa. Sin estas consideraciones, es difícil vislumbrar propuestas pedagógicas capaces de incorporar la diversidad - sin discriminación de clase, género, etnia o raza-, que promuevan una educación crítica, comprometida e igualitaria en la sociedad.

El desarrollo de una EMC supone puntos de partida y posicionamientos pedagógicos que conduzcan a un proceso de enseñanza y aprendizaje que permita pensar, problematizar, cuestionar lo dado. Las perspectivas pedagógicas críticas permiten analizar 
las propias posiciones, así como la influencia que se ejerce en los alumnos. Proponen desarrollar nuevas teorías de la práctica educativa que cuestionen aquello que se da por descontado en el conocimiento y en las prácticas escolares. Por tanto, el conocimiento se convierte en algo importante en la medida en que ayuda a comprender los presupuestos en los que se asienta y los procesos por los que ese conocimiento se produce, asimila y transforma dentro de contextos sociales e históricos específicos. Se trata de entender el conocimiento como una construcción social que encarna determinados intereses, está atravesado por relaciones de poder y que no es neutral ni objetivo, en el sentido tradicional del término.

Una educación que enseña a pensar y que promueve el desarrollo del pensamiento crítico supone respetar las comprensiones del mundo de los sujetos que participan en el proceso de enseñanza y aprendizaje, dar lugar a las distintas voces, tomar en cuenta sus experiencias previas, abrir espacios para cuestionar lo dado, hacer lugar a lo diferente, lo divergente, lo que ha sido puesto fuera de los márgenes mediante operaciones de naturalización. Implica espacios de exploración e investigación y de trabajo en equipo y colaborativo, de cocreación, que desafíen el sentido común y trasciendan el espacio del aula.

Las escuelas son espacios sociales de cultura y no lugares de reprobación y negación de las experiencias culturales de los sujetos (Llaver, 2019). Por ello, se trata de partir de la propia práctica de otros para construir el conocimiento desde experiencias colectivas/comunitarias y reflexionar sobre los propios haceres y decires. Se trata de que los sujetos digan su palabra y para ello es necesario habilitar espacios de escucha y de diálogo, como camino para sentar algunas bases de una educación crítica, que cuente con los docentes como guía, pero no como jueces del gusto de los jóvenes en relación con sus consumos mediáticos y tecnológicos.

\section{PRESUPUESTOS DE UNA EDUCACIÓN MEDIÁTICA CRÍTICA}

Roger Silverstone $(2004,2010)$, notable estudioso de los medios en su relación con la vida cotidiana, ha señalado que no solamente se debe asumir la realidad de estar puestos en un orden moral mediáticamente construido, sino que hay que tener la posibilidad de reconocerlo y, eventualmente, transformarlo, aceptarlo, rechazarlo, dialogar o discutir con él. El desarrollo de la educación mediática es condición de posibilidad de la interacción diversa con dicho orden moral, ese que dice quiénes son los buenos, los malos, los deseados, cuál es la mejor forma de ser mujer, quiénes son los ganadores y los perdedores, qué está bien y qué está mal y hasta cómo ser felices en el mundo en que vivimos.

Según Kellner y Share (2007), la educación mediática que evolucionó a partir de los estudios culturales es una estructura de comprensiones conceptuales que se caracteriza por presentar algunos elementos básicos: 
1) el reconocimiento de la construcción de los medios y de la comunicación como un proceso social, en oposición a aceptar textos como transmisores aislados de informaciones, neutros o transparentes; 2) algún tipo de análisis textual que explore los lenguajes, géneros, códigos y convenciones del texto; 3) una exploración del papel de las audiencias en la negociación de significados; 4) la problematización del proceso de representación para revelar y poner en discusión cuestiones de ideología, poder y placer; 5) un análisis de la producción de las instituciones y de la economía política que motivan y estructuran las industrias de los medios como negocios corporativos en busca de lucro. (pp. 64-65)

La EMC supone acciones que pongan en juego algunos aspectos:

- La desnaturalización de representaciones y sentidos mediáticos, operación que debe asociarse a la particularidad de los mensajes de los medios de ser productos de una industria de la información, el ocio y el entretenimiento. Esta perspectiva de la educación mediática crítica fue desarrollada fuertemente en los años 80 , cuando se abre paso lo que se denomina paradigma representacional, que puso en su centro cuestiones de política y poder. Roger Silverstone, en un sentido similar, habla de comprender la no transparencia de los medios, en virtud de las consecuencias que tiene la forma en que la realidad mediática atraviesa la textura de la experiencia: "En nuestra inocencia mediatizada, no nos es posible reconocer cuán enceguecidos estamos por las mediaciones que aparentemente nos vinculan" (Silverstone, 2004, p. 444).

La desnaturalización, en síntesis, es la visibilización del carácter construido de las representaciones mediáticas, a partir del análisis de la trama de relaciones de poder e intereses que se ponen en juego y sustentan un tipo de representación por sobre otra como si fueran naturales, teniendo en cuenta, además, que dichas representaciones existen y se sostienen en otros espacios no necesariamente mediáticos. La producción de estereotipos, por ejemplo, no se produce en el aire: se apoya en ciertos valores dominantes de las sociedades capitalistas contemporáneas. El análisis textual, según señala Kellner y Share (2005), debe expandirse para incluir aspectos del contexto social, el control, la resistencia, el poder, el placer. Se trata de desafiar las nociones relativistas y apolíticas que guían a algunos profesores y estudiantes para avanzar en exploraciones de cómo el poder y la información (o el entretenimiento) están conectados y vinculados. Las formas estereotipadas, además, son centrales en la producción industrial de cultura en virtud de la necesidad de reducir la complejidad, de promover perspectivas uniformes, para una más fácil circulación y consumo, y para evitar la problematización y generar una normalización de formas de ver el mundo conforme a jerarquías ya establecidas (Justo von Lurzer, 2011). 
- La inclusión de dimensiones cruciales como el género, la raza, la clase o las sexualidades en la comprensión del funcionamiento de los medios. El trabajo que la educación mediática crítica se propone en relación con las subalternidades y los prejuicios guarda estrecha relación con las consecuencias de vivir en un ambiente mediático. Roger Silverstone (2004) ha señalado que la distancia que los medios de comunicación proponen en la relación entre las personas no es solo una distancia material o geográfica, sino fundamentalmente social. Los medios proponen un "otro" o una "otra" extremadamente distantes, al punto del descompromiso total o, por el contrario, con tanta cercanía que se integran al propio mundo de un modo que anula toda posibilidad de reconocimiento de la alteridad. En ambos casos, lo que se pierde es el sentido de comunalidad y de diferencia bajo la forma de sujetos representados en formas homogeneizadas y naturalizadas, arrojados a puntos ciegos de nuestro campo de visión o a los que anulamos mediante una identificación plena.

- La consideración de la naturaleza comercial del sistema de producción de información y entretenimiento. Kellner y Share (2005) afirman: "Con demasiada frecuencia, los estudiantes creen que el papel de los medios es simplemente entretener o informar, con poco conocimiento de la estructura económica que los apoya" (p. 376). Los medios de comunicación pueden ser comprendidos en términos de actores económicos, especialmente a partir de la convergencia entre tecnologías, economía y comunicación. Esta perspectiva abre, además, la discusión acerca de la constitución de los ciudadanos en meros consumidores, debate que la EMC promueve.

- La incorporación de procesos de alfabetización informacional, mediática y digital que permitan nuevas formas de expresión. La alfabetización no es meramente instrumental, sino que responde al objetivo de empoderamiento de los sujetos para la producción de sus propios mensajes y formas de representación de la realidad, partiendo de la explicitación de la no neutralidad de la tecnología y sus usos. La alfabetización no es una actividad neutral sino una práctica socialmente construida y sostenida fundamentalmente en el ámbito educativo (aunque no solo en él), que responde a los cambios sociales y culturales y a los intereses de las élites que controlan las instituciones y sus prácticas (Kellner y Share, 2005), y que se integra en el conjunto más amplio del proceso educativo. No habría una alfabetización y una educación mediáticas que pudieran producirse por fuera de estas condiciones y de manera global y universal. Es necesario, por el contrario, pensarlas y definirlas en el marco del funcionamiento de los medios locales, las políticas públicas y normas que los regulan, las formas de promoción del derecho a la comunicación, los objetivos de la escuela en el contexto de una nación (y con ellos, lo que alienta y lo que anula o deja de lado), las relaciones 
entre cultura mediática y cultura escolar, por mencionar solo algunos aspectos. Incluso resulta imprescindible pensarlas a la luz de las discusiones relevantes en el campo comunicacional acerca de la cultura mediática, la ciudadanía comunicacional y el derecho a la comunicación, porque es allí donde encuentran su fundamento las acciones de educación para los medios (Martino, 2019).

- La visibilización de formas alternativas de rutinas de trabajo y de producción de contenidos (de información y entretenimiento), de establecimiento de agendas mediáticas y de representación de la realidad, y no solamente la referencia a formas hegemónicas de producción de mensajes. Para promover producciones alternativas es necesario conocer, analizar, experimentar la forma en que los medios barriales, comunitarios o no hegemónicos funcionan y las concepciones de la comunicación que poseen los actores que los integran.

La EMC constituye, por sobre todo, un proyecto político. Y su carácter crítico no deviene simplemente del objetivo que se propone en relación con los sujetos a los que dirige sus acciones, sino de los posicionamientos previos para emprender tal tarea.

\section{UNA INTERPELACIÓN AL DISEÑO CURRICULAR PROVINCIAL DESDE LA PERSPECTIVA DE LA EDUCACIÓN PARA LOS MEDIOS CRÍTICA}

Como se expuso inicialmente, en el trabajo de investigación fueron sistematizados los contenidos del diseño curricular de la materia Comunicación Social priorizados para su enseñanza, así como las formas habituales en que estos eran trabajados por profesores. En la tabla que sigue se vuelca la información obtenida. Para su construcción se tuvieron en cuenta los dos ejes definidos en el documento curricular oficial (ver tabla 1), aunque en cada eje se tomaron como referencia los saberes tal y como están siendo adaptados por los profesores de comunicación. Se trata de contenidos que destacan como saberes priorizados en su propia práctica docente y que, además, son los que aparecen en materiales de trabajo elaborados por ellos mismos. Al lado de cada conjunto de saberes se refieren, además, las estrategias didácticas que usualmente son utilizadas (ver tabla 2).

A partir de esta caracterización surge la pregunta acerca de cómo podrían introducirse, utilizando el diseño curricular vigente, perspectivas que den cuenta de los postulados de la educación mediática crítica (descritos en el punto 6 de este artículo). Se ofrecen, a continuación, algunas propuestas y sugerencias.

En relación con el eje 1, referido a la comunicación como práctica social, se consideró fundamental abrir el juego a otros modelos menos esquemáticos para pensar los procesos de comunicación. Asimismo, resultaría interesante problematizar los procesos comunicativos que se dan en el mismo ambiente escolar: ¿Cómo son las situaciones de comunicación en la escuela? ¿Entre quiénes se dan? ¿Quién tiene prioridad en la toma de la palabra? ¿Qué asimetrías, relaciones de poder, de diálogo o de cocreación pueden identificarse? 
Tabla 2

Saberes priorizados y principales estrategias didácticas en la enseñanza de la comunicación

\section{Saberes priorizados en la enseñanza Estrategias didácticas encontradas de la comunicación}

Eje 1. La comunicación como práctica social

$\begin{array}{ll}\text { Modelos de comunicación (clásico y } & \text { - Uso de diagramas para explicar modelos de comunicación, } \\ \text { semiótico) } & \text { diferenciar elementos y relaciones entre ellos. } \\ \text { Elementos del proceso de la } & \text { - Uso de ejemplificaciones y simulación de casos para } \\ \text { comunicación } & \text { identificar procesos, elementos, relaciones, tipos de } \\ \text { Relaciones entre elementos del proceso } & \text { comunicación, contextos. } \\ \text { de la comunicación } & \text { - Acento puesto en procesos de comunicación interpersonal. } \\ \text { Tipos de comunicación y de situaciones } & \text { - Uso de clasificaciones y tipologías. } \\ \text { comunicativas } & \text { - Creación de los propios ejemplos por parte de alumnos } \\ \text { Contextos de comunicación } & \text { según indicaciones de profesores en relación con los } \\ \text { Vínculos posibles en las relaciones de } & \text { modelos, elementos y tipologías enseñadas. } \\ \text { comunicación } & - \text { Actividades centradas en el reconocimiento, la descripción } \\ \text { Análisis crítico y producción de mensajes } & \text { y la identificación. }\end{array}$
en diferentes formatos y soportes

Eje 2. La comunicación y los medios masivos

\begin{tabular}{|c|c|}
\hline Historia de los medios & $\begin{array}{l}\text { - Uso de cronologías y líneas de tiempo. } \\
\text { - Establecimiento de relaciones entre hitos históricos y } \\
\text { contextos sociopolítico y económico de surgimiento de cada } \\
\text { medio. } \\
\text { - Establecimiento de relaciones de comparación entre } \\
\text { medios en términos de sus alcances, posibilidades de } \\
\text { retroalimentación, etc. }\end{array}$ \\
\hline $\begin{array}{l}\text { Particularidades de la propaganda y la } \\
\text { publicidad en relación con los medios }\end{array}$ & $\begin{array}{l}\text { - Distinción entre propaganda y publicidad, funciones de } \\
\text { cada una. } \\
\text { - Identificación y reconocimiento de elementos constitutivos. } \\
\text { - Introducción del problema de los estereotipos en la } \\
\text { publicidad desde una perspectiva crítica. } \\
\text { - Uso de ejemplos de publicidad/propaganda gráfica o } \\
\text { audiovisual para el análisis, mayoritariamente de aparición } \\
\text { en grandes medios. } \\
\text { - En algunos casos, alusión a la sociedad de consumo y sus } \\
\text { implicaciones. } \\
\text { - Producción de publicidades/propagandas. } \\
\text { - Análisis de la representación de los jóvenes en la publicidad. }\end{array}$ \\
\hline $\begin{array}{l}\text { La imagen, asociada al análisis } \\
\text { de representaciones sociales y } \\
\text { reconocimiento de estereotipos }\end{array}$ & $\begin{array}{l}\text { - Abordaje teórico-conceptual en relación con la imagen. } \\
\text { - Desarrollo de precisiones conceptuales acerca de qué es } \\
\text { una representación y un estereotipo. } \\
\text { - Análisis de estereotipos y representaciones sociales en los } \\
\text { medios y en la publicidad, sobre todo, análisis de imágenes. } \\
\text { - Se trabaja fundamentalmente con la noticia y la publicidad. } \\
\text { - Predominio de análisis semiótico-textual. }\end{array}$ \\
\hline
\end{tabular}




\begin{tabular}{|c|c|}
\hline & $\begin{array}{l}\text { - Principalmente, se trabaja noticia: concepto, función, } \\
\text { elementos. La noticia como construcción. }\end{array}$ \\
\hline $\begin{array}{l}\text { Géneros discursivos mediáticos y } \\
\text { resignificaciones a través de las TIC }\end{array}$ & $\begin{array}{l}\text { - Se introduce también el tema de la imagen (concepto, } \\
\text { características, tipologías, relación con distintos medios). }\end{array}$ \\
\hline $\begin{array}{l}\text { Análisis de uso e impacto de nuevas } \\
\text { tecnologías como medios masivos }\end{array}$ & $\begin{array}{l}\text { - Desarrollo de conceptualizaciones respecto de las TIC, } \\
\text { particularmente internet y redes sociales (se observa el } \\
\text { paso del trabajo de Facebook a Instagram, dado que los } \\
\text { jóvenes se han "mudado" de red). }\end{array}$ \\
\hline & $\begin{array}{l}\text { - Abordaje sistemático de riesgos y peligros de las redes } \\
\text { sociales, en relación, sobre todo, con problemáticas que } \\
\text { cursan los jóvenes y que son abordadas en la escuela (por } \\
\text { ejemplo, bullyng, relaciones sexoafectivas). }\end{array}$ \\
\hline $\begin{array}{l}\text { Producción de mensajes en variedad de } \\
\text { géneros, formatos y soportes }\end{array}$ & $\begin{array}{l}\text { - Mayor espacio de creatividad de los docentes. Se abre } \\
\text { un espectro muy amplio de variedad de producción de } \\
\text { mensajes que no permite marcar una tendencia. Las } \\
\text { propuestas de producción incluyen: fotorrelato, diario } \\
\text { mural, audiovisual, spot radial, creación de página de } \\
\text { Facebook, creación de blog, fotografía estenopeica, afiche, } \\
\text { historieta, animación. }\end{array}$ \\
\hline
\end{tabular}

Elaboración propia

El trabajo con simulación de casos, una de las estrategias didácticas encontradas, mencionada en la tabla 2, puede ser muy útil para los efectos descriptivos y de identificación de elementos del proceso, pero corre el riesgo de convertirse en un "artefacto" cuya utilidad se reduce a la de constatar que los estudiantes hayan retenido taxonomías, elementos, relaciones, desenraizadas de la complejidad del proceso de la comunicación. Las experiencias vividas por los estudiantes, e incluso en conjunto con sus docentes, resultan potentes en términos de identificar cómo la comunicación puede ser diálogo, manipulación, imposición, coproducción, intercambio fructífero o agresión.

En este punto, el contenido propuesto por el currículo podría ser la oportunidad de tematizar las cuestiones relacionadas con las dimensiones de poder en las relaciones entre los sujetos, pero también, en las relaciones entre grupos sociales dominantes/ dominados. Asimismo, permite identificar funcionamientos similares a los de la comunicación interpersonal en los medios masivos de comunicación. Los contextos en los que se da la comunicación (la escuela, la familia, los grupos de pares, con autoridades) también pueden ayudar a identificar asimetrías y desigualdades en la toma de la palabra y los motivos en que se fundamentan.

La observación participante es una estrategia que también podría ser utilizada en reemplazo del análisis de ejemplos o casos, y que puede resultar mucho más rica en términos del análisis y de la posibilidad de involucrar las propias comprensiones y 
sentimientos respecto de las diversas situaciones comunicativas que se desarrollan en la vida cotidiana de los jóvenes.

Respecto del eje 2, sobre la comunicación y los medios masivos, se abordarán algunos temas separadamente.

En relación con la historización de los medios de comunicación, resulta relevante preguntarse cuál es el sentido de enseñar una historia de los medios más allá de lo anecdótico. Si bien los docentes establecen relaciones entre dicha historia y el contexto sociohistórico de surgimiento, cabría preguntarse además cuáles de esas relaciones podrían resultar significativas para un joven. Otro aspecto para tener en cuenta es el de incluir, en dicha cronología, referencias a otras formas de la comunicación como la literatura de cordel, el colportage, los relatos orales, los medios alternativos, comunitarios e incluso escolares (radio, diario mural), que tienen una trayectoria significativa en América Latina y que no forman parte de las "historias oficiales".

Una historia de los medios de comunicación debe incluir, además, algunas problematizaciones acerca de la propiedad, el derecho a la comunicación o la importancia de estos para el funcionamiento de la democracia y la construcción de ciudadanía, y poner en juego los conceptos de ideología e interés, así como la dimensión mercantil de la comunicación mediática y de los ecosistemas de medios conectivos (Van Dijck, 2016).

Un tema que concentra bastante tiempo y atención por parte de los docentes es el de la propaganda y la publicidad. En un momento en que la juventud es interpelada en forma insistente como consumidora, la temática ofrece una oportunidad invaluable para explicitar las relaciones entre publicidad, sociedad de consumo y jóvenes. ¿Cómo se dirige la publicidad a los jóvenes y cómo los presenta? ¿Cómo atraviesan las publicidades su vida cotidiana, como intersectan en forma permanente las pantallas, las aplicaciones, los dispositivos que utilizan? ¿En qué otros espacios sienten que solamente son considerados como consumidores?

Habitualmente, el trabajo con los conceptos de propaganda y publicidad hace hincapié en las diferencias entre ambos, pero ¿sería posible pensar en cómo cada vez más se confunden, como en el caso de las campañas políticas? ¿0 analizar "contrapublicidades"? ¿O investigar cómo son las propagandas y las publicidades en los medios no hegemónicos (revistas digitales independientes, canales y radios comunitarias)? El tema invita también a pensar en la mercantilización de la vida de los jóvenes, utilizando experiencias que les son cercanas: desde el merchandising asociado a los útiles escolares hasta los viajes de egresados y las cenas de fin de curso que movilizan toda una industria destinada a ellos, que se apoya sobre la base del consumo de apariencias y experiencias emocionales.

Las publicidades son el ámbito en el que con más facilidad se pueden analizar estereotipos sociales. De la mano de estos estereotipos y sus rasgos salientes, es necesario 
ahondar en las discriminaciones que promueven y los prejuicios que ponen a circular en relación con las mujeres, los pobres, los inmigrantes, el color de piel, las zonas de la ciudad donde se habita, la gente del campo, etc. Tal como lo ha señalado Carolina Justo von Lurzer (2011), abordar los estereotipos por fuera del universo mediático ${ }^{10}$ permite reflexionar y ampliar la comprensión de los mecanismos de clasificación social y su función de valoración y jerarquización de sujetos y prácticas y los marcos de inteligibilidad que proveen. Como bien lo ha señalado la autora, es necesario promover un análisis sociocomunicacional por sobre uno semiótico-textual, que es tal vez hoy el más extendido.

Otro tema abordado o priorizado por los docentes es el de los géneros mediáticos y su resignificación a través de las TIC y el análisis de uso e impacto de nuevas tecnologías como medios masivos. Los temas relacionados con las nuevas tecnologías no siempre logran en el ámbito escolar un tratamiento que acompañe la presencia que adquieren en la vida cotidiana de los jóvenes. Ejemplo de esto son las disputas por el uso del celular en el aula o los prejuicios en relación con el uso que hacen de las redes sociales o selfies, sin ahondar en los significados (relacionales, emocionales, afectivos) que tienen estos usos y consumos juveniles, a la vez que enfatizando solo sobre sus peligros.

Esta situación invita a pensar: ¿Cómo problematizar las tecnologías sin caer en una posición moralista o proteccionista como la que, en sus orígenes, caracterizó a la educación para los medios? ¿Cómo superar la visión de las TIC como herramientas neutras cuyo impacto depende del buen o mal uso que se haga de ellas y avanzar hacia una reflexión sobre el carácter prescriptivo de toda tecnología?

Hoy resulta fundamental visibilizar, entre esas tantas prescripciones, aspectos que invaden la vida de los jóvenes: la invitación a mostrar y a ver todo, a estar siempre disponibles; los peligros de volverse transparentes, de proveer toda su información y someterse inadvertidamente a todo tipo de controles y vigilancia por parte de las grandes corporaciones de la comunicación; el imperativo de ser halagados, likeados, de ser elegidos o rankeados en los sitios para hacer amigos o conseguir citas y sus relaciones con las concepciones acerca del éxito y la felicidad.

Se trata, si se quiere promover una perspectiva crítica, de abandonar el paradigma de las tecnologías como herramientas para inscribirlas en sus contextos de producción y uso.

Finalmente, están los aspectos relacionados con la producción de mensajes en variedad de géneros, formatos y soportes. Se ha mencionado que, en este punto, los docentes muestran su capacidad de crear e innovar. Tal vez el mayor desafío aquí sea al nivel de los contenidos que trasuntan estas producciones, así como de la valoración del

10 Los estereotipos trascienden a los medios masivos tradicionales y se hacen presentes en otros géneros y formatos de consumo juvenil: videojuegos, aplicaciones del celular, canales de YouTube, en las redes a través de los memes y hasta en los discursos de los influencers. 
proceso de producción más que del producto final, siempre tensionado por las expectativas de la institución escolar.

\section{CONCLUSIONES}

Tal como se ha señalado, en cualquier selección de contenidos para la enseñanza intervienen distintas instancias de decisión social (el campo cultural, el Estado, incluso el mercado) y que no solamente se ponen en juego criterios de orden pedagógico. El currículo expresa tensiones, luchas, jerarquías, diversidad, desigualdades, exclusiones, y lo que finalmente se selecciona y organiza como contenidos a enseñar es lo que se considera valioso y válido en un momento determinado. Pensarlo en estos términos es lo que permite interrogarlo, atravesarlo reflexiva y críticamente, trabajar sus potencialidades, sus hermetismos, lo que está presente y ausente, lo que puede ser resignificado.

El contenido a enseñar encuentra su concreción en la interpretación que realiza el docente en el momento de planificar su tarea y de presentar sus clases y es por eso que, lejos de pensarlo como una estructura cerrada, inmodificable y rígida, es posible visualizarlo como una trama con grietas e intersticios, moldeable, pasible de ser transformado.

Si bien la administración central y las instancias decisoras ocupan en la jerarquía un lugar privilegiado, los profesores pueden convertir la situación de enseñanza en un espacio de oportunidades para el despliegue de tácticas, de "vagabundeos eficaces" (De Certeau, 2000), de reapropiación de los contenidos objetivados en ese documento rigidizado que puede ser el currículo. El cotidiano escolar representa un mundo "otro", que día a día es poseído, tejido, unido, pensado y hecho (Alves, 1998, p. 51) y que funciona como un ámbito propicio para la praxis transformadora no solo en la enseñanza de la comunicación, sino de cualquier otro contenido escolar.

Finalmente, resulta necesario señalar la responsabilidad que deben asumir aquellas instituciones exteriores a la escuela que funcionan como referencia y autoridad cultural en materia de comunicación. En el caso de las universidades, como instancias de formación y producción de conocimientos, resulta fundamental que provean espacios de reflexión y herramientas para propiciar dicha praxis transformadora. Se espera, con la propuesta aquí presentada, haber contribuido en algo con ese objetivo.

\section{REFERENCIAS}

Alves, N. (1998). O espaço escolar e suas marcas. O espaço como dimensão material do currículo. Río de Janeiro: DP\&A Editora.

Apple, M. (1989). Maestros y textos. Una economía política de las relaciones de clase y de sexo en educación. Madrid: Paidós/MEC. 
Buckingham, D. (2005): Educación en medios. Alfabetización, aprendizaje y cultura contemporánea. Barcelona: Paidós.

Da Silva, T. (1997). Cap. 3. Descolonizar el currículo: estrategias para una pedagogía crítica (Dos o tres comentarios sobre el texto de Michel Apple). En Apple, M.; Tadeo da Silva, T. Gentili, P., Cultura, política y currículo. Buenos Aires: Losada.

Da Silva, T. (1999): Documentos de identidad. Una introducción a las teorías del currículo. Belo Horizonte: Autêntica Editorial.

De Certeau, M. (2000). La invención de lo cotidiano I. Artes de hacer. México: Universidad Iberoamericana. Departamento de Historia. Instituto Tecnológico y de Estudios Superiores de Occidente.

Dirección General de Escuelas-Gobierno de Mendoza. (1999). Renovación curricular en la provincia de Mendoza. Educación Artística y Comunicación Social. Propuesta curricular de Educación Artística y Comunicación Social para el Tercer Ciclo de la Educación General Básica.

Diseño Curricular Provincial. Secundario. Bachiller en Comunicación [DCP]. (2015). Dirección General de Escuelas, Subsecretaría de Planeamiento y Evaluación de la Calidad Educativa, Dirección de Planificación de la Calidad Educativa. Ministerio de Educación del Gobierno de Mendoza.

Freire, P. (1977). Pedagogía del oprimido. Bogotá: Siglo XXI.

Freire, P. (1993). Pedagogía de la esperanza. Buenos Aires: Siglo XXI.

Giroux, H. (1990). Los profesores como intelectuales. Hacia una pedagogía crítica del aprendizaje. Barcelona: Paidós.

Giroux, H. (1992). Cruzando límites. Trabajadores culturales y políticas educativas. Barcelona: Paidós.

Giroux, H. (2004). Teoría y resistencia en educación. Una pedagogía para la oposición. México: Siglo XXI - UNAM.

Gvirtz, S. y Palamidessi, M. (1998). El ABC de la tarea docente: Currículo y enseñanza. Buenos Aires: Aique.

Justo von Lurzer, C. (2011). Capítulo 6: El cliché de los estereotipos. ¿Por qué y cómo abordarlos? En: Margiolakis, E. y Gamarnik, C, Enseñar comunicación: dilemas, desafíos y posibilidades. Buenos Aires: La Crujía.

Kellner, D. (1998). Multiple literacies and critical pedagogy in a multicultural society. Educational Theory 48(1), 103-122.

Kellner, D. (2011). Cultura mediática: estudios culturales, identidad y política entre lo moderno y lo posmoderno. Madrid: Ediciones Akal. 
Kellner, D. y Share, J. (2005). Toward Critical Media Literacy: Core concepts, debates, organizations, and policy. Discourse: studies in the cultural politics of education, 26(3), 369-386.

Kellner, D. y Share, J. (2007). Critical media literacy is not an option. Learn Inq 1, 59-69.

Ley Federal de Educación 24.195, Boletín Oficial de la República Argentina, 5 de mayo de 1993.

Ley de Educación Nacional 26.206, Boletín Oficial de la República Argentina, 28 de diciembre del 2006.

Llaver, N. (2019). El currículo escolar visto desde el Sur. En Llaver, N., Martino, B. y otros, Comun(Y)qué. Pensar críticamente la enseñanza de la comunicación. En prensa.

Llaver, N. y Martino, B. (2017). La enseñanza de la comunicación en la escuela secundaria. Resignificación del currículum desde la educación mediática crítica. Informe final presentado y aprobado. Secretaría de Ciencia Técnica y Posgrado, Universidad Nacional de Cuyo, Mendoza, Argentina.

Martino, B. (2019). La configuración del espacio de enseñanza de la comunicación en la escuela secundaria en Mendoza: desafíos disciplinares y de la profesión. Tesis para aspirar al grado de Doctora en Ciencias Sociales - Mención Comunicación. En curso.

Masterman, L. (1993a). La enseñanza de los medios de comunicación. Madrid: Ediciones de la Torre.

Masterman, L. (1993b). The media education revolution. Canadian Journal of Educational Communication, 22(1), 5-14.

Mc. Laren, P. (1984). La vida en las escuelas: una introducción a la pedagogía crítica en los fundamentos de la educación. México D. F.: Siglo XXI.

Morduchowicz, R. (2017). Media Literacy in Latin America. The Argentine Experiencie. En: B. S. de Abreu, P. Mihailidis, A. Y. L. Lee, J. Melki, y J. McDougall (Eds.). International Handbook of Media Literacy Education. Nueva York: Routledge.

Silverstone, R. (2004). ¿Por qué estudiar los medios? Buenos Aires, Amorrortu.

Silverstone, R. (2010). La moral de los medios de comunicación. Sobre el nacimiento de la polis de los medios. Buenos Aires: Amorrortu.

Taylor, S. y Bogdan, R. (1994). Capítulo 4. La entrevista en profundidad. Introducción a los métodos cualitativos de investigación. Barcelona: Paidós.

Van Dijck, J. (2016). La cultura de la conectividad: Una historia crítica de las redes sociales. Buenos Aires: Siglo XXI. 